\title{
A força do Direito: roteiros de pesquisa em sociologia do campo jurídico
}

\author{
The Force of Law: research routes in sociology \\ of the juridical field
}

Felipe Araújo Castro

\begin{abstract}
Resumo: Apesar da existência de uma produção acadêmica já consolidada, feita a partir do marco teórico da sociologia relacional bourdieusiana - ou com referência a ele - e que tem o momento jurídico enquanto objeto de investigação, as contribuições do autor francês à análise do campo jurídico parecem não reverberar nos limites das ciências jurídicas. Com efeito, os juristas e o campo jurídico foram objetos de considerações acessórias em variados momentos da obra do autor, mas foi em $A$ força do direito que Pierre Bourdieu traçou uma espécie de teoria sociológica geral do Direito. Nossa hipótese é (i) que esse ensaio
\end{abstract}

1 Doutor pela UFMG (2018), onde defendeu tese acerca da genealogiahistórica do campo jurídico nacional, sustentando que um pensamento liberal conservador, uma reprodução aristocrática da burocracia jurídica e uma prática forense autoritária são traços característicos de toda a experiência jurídica nacional. Atualmente é Professor Adjunto na Universidade Federal Rural do Semi-Árido, atuando principalmente na interfaces entre direito, sociologia e filosofia. 
deve ser lido mais como uma espécie de roteiro de pesquisas, no sentido de levantar dúvidas e hipóteses passíveis de comprovação ou refutação, do que um repositório de respostas prontas e acabadas sobre as relações de poder que incidem sobre o campo jurídico e (ii) que a sua devida recepção pelas ciências jurídicas no Brasil seria capaz de auxiliar o desvelamento do caráter fortemente conservador do campo jurídico nacional. Para comprovação da hipótese reconstruiremos os principais argumentos do autor, (a) acerca da necessidade de emergência de uma ciência rigorosa do direito, (b) sobre as divisões e disputas internas do campo como condição de mistificação do discurso jurídico e (c) sua compreensão sobre os poderes performativos dos atos jurídicos - cotejando-os com a produção acadêmica externa ao direito. Esses debates, via de regra, estão ausentes da formação jurídica nacional, contribuindo para a conservação da hegemonia de teorias tradicionais do direito, que têm em comum o fato de enevoarem as disputas políticas, econômicas e culturais que estão na base da produção e aplicação jurídica.

Palavras-chave: Pierre Bourdieu; Sociologia Relacional; Campo Jurídico; Sociologia Jurídica.

Abstract: The contributions of Pierre Bourdieu oeuvre to the analysis of the legal field do not seem to reverberate properly within the confines of the legal sciences, despite the existence of an already consolidated academic production, made from the theoretical framework of a Bourdieusian relational sociology that has the legal act as an object of investigation. Indeed, jurists and the legal field were objects of ancillary considerations at various times in the author's work, but it was in The Force of Law that Pierre Bourdieu traced a kind of general 
sociological approach of the current theories of law. Our hypothesis is (i) that this seminal essay should be read more as a research script, capable of raising doubts and hypotheses that can be verified or refuted, than a repository of ready-made answers about the power relations within the legal field and (ii) that its proper reception by the legal sciences in Brazil would be able to help unveiling the strongly genetic conservative character of the national legal field. To verify our hypothesis we will firstly reconstruct the author's main arguments, (a) about the necessity of the emergence of a rigorous science of law, (b) about the divisions and internal disputes within the field as a condition of mystification of the legal discourse and (c) its comprehension about the performatives powers of legal acts. These fundamental debates, as a rule, are absent from national legal formation or are extremely marginalized, what ends contributing to the preservation of a hegemony of traditional theories of law - these theories have in common the fact that they blur the political, economic and cultural disputes that underlie legal production and application.

Keywords: Pierre Bourdieu; Relational Sociology, Legal Field, Sociology of Law.

\section{Introdução}

Pierre Bourdieu é um dos mais importantes sociólogos do século XX e, a essa altura, já dispensa maiores apresentações. ${ }^{2}$ Entretanto, a entrada do autor na ciência do direito

2 Sobre esse ponto, remetemos o leitor especialmente à auto-análise do autor em BOURDIEU, Pierre. Esboço para uma auto-análise. Tradução de Victor Souza. Lisboa: Edições 70, 2005, a um documentário sobre sua vida e obra em CARLES, Pierre. La sociologie est um Sport de combat. França: C. F. Productions; V. F. Productions, 2001, além de toda bibliografia 
é ainda muito incipiente. As melhores intervenções sobre o momento jurídico, feitas a partir do marco da sociologia relacional bourdieusiana, são frequentemente exógenas ao campo; contribuições de sociólogos, cientistas políticos etc. ${ }^{3}$

Não obstante, o direito constitui um tema importante da obra de Bourdieu, ainda que não tenha dedicado um trabalho específico sobre o campo - como fez em relação às áreas da educação, da cultura e do poder estatal -, o campo jurídico sempre atravessou as suas principais obras sobre o Estado. ${ }^{4}$

A única contribuição específica do autor ao campo jurídico é um texto curto, porém bastante denso e já clássico, intitulado A Força do Direito: elementos para uma sociologia do campo jurídico. ${ }^{5}$ A obra foi publicada em português na coletânea O Poder Simbólico, em meio a outros textos que dialogam intensamente com a prática e linguagem jurídica, abrangendo desde discussões sobre o poder simbólico, passando pelas noções das categorias de habitus e campo até os elementos constitutivos do campo estatal.

de comentadores nacionais e internacionais, citada ao longo do texto.

3 Ver, entre outros, as principais contribuições diretamente referenciadas no trabalho, como AZEVEDO, Rogrido G. A força do direito e a violência das formas jurídicas. Revista de Sociologia Política, v. 19, n. 40, 2011, Azevedo (2011), MIGUEL, Luiz Felipe. Bourdieu e o "pessimismo da razão". Tempo Social, v. 27, n.1, 2014 Miguel (2014) e SCKELL, Soraya Nour. Os juristas e o direito em Bourdieu: a conflituosa construção histórica da racionalidade jurídica. Tempo Social, v. 28, n 1, 2014.Sckell (2014).

4 Especialmente em A nobreza do Estado (BOURDIEU, Pierre. La nobleza del Estado: educación de elite y espíritu de cuerpo. Traduzido para o espanhol por Alicia Gutiérrez. Buenos Aires: Siglo Veintinuo, 2013 e seus cursos sobre o Estado em BOURDIEU, Pierre. Sobre o Estado: cursos no Collège de France (1989-1992). Tradução de Rosa D’Aguiar. São Paulo: Companhia das Letras, 2014.

5 BOURDIEU, Pierre. A força do direito: elementos para uma sociologia do campo jurídico. In: Pierre Bourdieu. O poder simbólico. Tradução de Fernando Tomaz. Rio de Janeiro: Bertrand Brasil, 1989a. 
Nosso objetivo, ao destrinchar o texto em questão, é demonstrar como A Força do Direito, em coerência com as posições do autor dentro do campo intelectual, sobretudo no que concerne à refutação das "grandes teorias" e da defesa intransigente de uma sociologia relacional radical, ${ }^{6}$ constitui um excelente roteiro de pesquisas na área da sociologia jurídica e, desde que devidamente mediado em deferência ao contexto sócio-histórico nacional, pode contribuir para a consolidação e desenvolvimento de uma sociologia jurídica nacional capaz de realizar o que Bourdieu acreditava ser o verdadeiro sentido das ciências sociais: a desconstrução do senso comum (doxa) pela revelação do compromisso das práticas tradicionais na manutenção da ordem desigualmente e autoritariamente estabelecida. ${ }^{7}$

É importante destacar de imediato, no entanto, que essas possibilidades de emancipação frequentemente se apresentam muito mais modestas do que as utopias transformadoras gostam de descrever, sobretudo no que concerne ao papel dos juristas a partir do campo jurídico. ${ }^{8}$

\section{A Força do Direito}

Em seu texto $A$ força do direito, Bourdieu se debruça especificamente sobre o campo jurídico, sobre suas características e funções, realizando uma contribuição importante aos seus próprios estudos sobre o processo de emergência do Estado e da nobreza burocrática (lastreada pelo mérito distribuído nas escolas). Dessa forma, o texto não deve ser lido de maneira isolada, mas dentro da gramática sociológica

\footnotetext{
6 BOURDIEU, Pierre. Esboço para uma auto-análise. op. cit.

7 Pierre. Os usos sociais da ciência: por uma sociologia clínica do campo científico. Tradução de Denise Catani. São Paulo: Editora Unesp, 2004

8 MIGUEL, Luiz Felipe. Bourdieu e o "pesimismo da razão". op. cit..
} 
específica do autor; deve levar em consideração, portanto, os conceitos de poder e violência simbólica, campo, habitus, doxa etc. Bourdieu descreve a violência simbólica como um tipo de coação que não pode ser exercida sem a cumplicidade ativa daqueles sujeitos à dominação, o que não significa uma submissão consciente ou voluntária, mas antes elabora e depende da crença que os comandos aos quais estão submetido por normas sociais (sobretudo jurídicas) é, de certa forma, justo por que naturalizado. ${ }^{9}$

Portanto, o campo jurídico e os juristas que atuam dentro dos seus limites são fundamentais não apenas porque participaram decisivamente da formação do Estado moderno, mas porque continuam a manusear e administrar a linguagem pela qual se estabelecem as distinções e hierarquias dentro e fora vida estatal, sendo que aqueles que são excluídos da ordem jurídica, considerados como não portadores de direitos, estão igualmente submetidos ao Estado via repressão.

Antes de adentrar nos méritos do texto, no entanto, iniciaremos pela apresentação das críticas ao trabalho, que consiste, principalmente, na demonstração de certa reminiscência universalista na exposição do autor - apesar de seus frequentes esforços em refutar e recusar esse tipo de abordagem, visto que representariam o que autor chama pejorativamente de "grande teoria". Não obstante não ser uma questão capital, no sentido que venha a invalidar o conteúdo da intervenção como um todo, ainda assim, é importante reconhecer que mesmo os melhores esforços metodológicos não são infalíveis quando se trata de evitar preconcepções incorporadas. Portanto, tal crítica introdutória tem uma função metalinguística ao expor que não existe um método infalível, ao mesmo tempo que tal constatação, ou

$9 \quad$ BOURDIEU, Pierre. La nobleza del Estado. op. cit., p. 17. 
seja, a ausência de uma metodologia perfeita, não justifica o abandono dos esforços em busca do método mais adequado.

Com efeito, a partir de uma análise sucinta (e um tanto superficial) das principais tradições jurídicas do Atlântico Norte - a romano-germânica e a anglo-saxã - Bourdieu supõe identificar traços de "uma luta simbólica permanente" que estaria presente nos mais diferentes sistemas jurídicos, portanto, uma espécie de tendência universal dos campos jurídicos para tal disputa. Uma afirmação que contraria a perspectiva eminentemente materialista do autor, mais propensa a considerar os desenvolvimentos históricos de cada contexto específico.

Nosso intuito ao elaborar e apresentar essa crítica não é um mero exercício acadêmico, mas antes, serve de estratégia para ressaltar as peculiaridades do campo jurídico nacional que o diferenciam sobremaneira das grandes narrativas apresentadas por Bourdieu em A força do direito, indicando a necessidade de um tratamento específico para as estruturas jurídicas brasileiras e seus agentes.

$\mathrm{O}$ traço permanente que o autor enxerga em todos os campos jurídicos consiste em uma separação rígida entre teóricos e práticos no interior do campo - enquanto os primeiros tenderiam a um maior respeito pela letra da lei e pela vontade do legislador e atuariam pela elaboração de doutrinas e comentários a esses instrumentos, os segundos se aferrariam à potencialidade criativa do momento de aplicação do direito, ambos os grupos valorizando as suas próprias posições. Essa cisão teria por consequência a disputa entre esses dois polos pela hegemonia no campo, pelo monopólio de dizer ou determinar o direito.

No entanto, essa separação, como relatada, não se dá da mesma maneira nem com a mesma intensidade no campo jurídico brasileiro, o que conduz a uma dinâmica significa- 
tivamente diferente das relações sociais no interior desse espaço específico, com consequências importantes para a qualidade e intensidade de sua autonomia. Nesse sentido, o modelo descritivo do sociólogo francês não passa de um modelo, através do qual enxergaremos uma realidade particular, e não uma narrativa transhistórica do campo jurídico considerado abstratamente.

Nosso objetivo é então apresentar as principais ideias desse texto seminal, procurando identificar quais considerações feitas por Bourdieu, em relação ao campo jurídico, geralmente se aplicam ao contexto nacional, quais não se aplicam, quais se aplicam apenas parcialmente e quais demandam mediações em atenção ao cenário local.

Apesar das críticas realizadas, $A$ força do direito consiste em uma importante e original contribuição para a sociologia do campo jurídico, ainda não suficientemente assimilada pelas ciências jurídicas. ${ }^{10}$ As reflexões ali contidas oferecem

10 A Força do Direito já foi analisado com vistas à sua aplicação ao campo jurídico nacional - assim como a obra de Bourdieu em geral -, notadamente por autores com formações e atuações majoritariamente externas ao campo, a exemplo dos trabalhos coletivos organizados por Fernando Fontainha, (2017, 2014, 2014) e os trabalhos de Frederico de Almeida $(2016,2015)$ e Fabiano Engelmann. (2006), mas também por outros Outros autores, com formação exclusivamente jurídica, também se dedicaram ao tema, como Soraya Sckell. (2014). Quanto asPara uma abordagemens mais específicas sobre o texto, ver o trabalho de Rodrigo Azevedo, A força do direito e a violência das formas jurídicas. Os trabalhos mencionados encontram-se nas referências desse trabalho. Azevedo (2011) trata do problema específico da distinção entre um campo jurídico e um campo judicial, colacionado referências à trabalhos ligados ao tema do campo da administração de conflitos dentro do Estado, notadamente ligados às ciências penais (criminologia e política criminal); enquanto Sckell (2014) se preocupa com a formação da racionalidade jurídica no Ocidente a partir de uma "reflexão internacional e multidisciplinar". Nossao trabalhocontribuição, por sua vez, volta-se mais especificamente sobre as potencialidades do desenvolvimento de uma sociologia rigorosa do direito no Brasil, destinado aqueles e aquelas com pretensões de desenvolver pesquisas nesse campo. 
um roteiro de pesquisa com inúmeras possibilidades de aprofundamento acerca das relações dos agentes jurídicos entre si e em relação ao próprio espaço social onde atuam.

\section{Uma ciência rigorosa do direito}

Seguindo o mesmo método de pesquisa desenvolvido em As regras da arte para analisar o campo artístico, ao observar o campo jurídico, Bourdieu busca superar as simplificações teóricas que o enxergam ora como um instrumento neutro de regulação e integração social, ora como mero instrumento de dominação social pelas elites. Da mesma forma que as noções de habitus e campo ${ }^{11}$ possibilitaram a superação das insuficiências do estruturalismo mecanicista e das teorias da ação racional para o campo da literatura, quando aplicadas ao campo jurídico, elas têm a potencialidade de contribuir para elaboração de "uma ciência rigorosa do direito", que se diferiria do que usualmente chama-se ciência jurídica, justamente por tomar-lhe como objeto de pesquisa e não como ciência autônoma. ${ }^{12}$

11 Para um aprofundamento das noções de campo e habitus remetemos o leitor aos originais do autor. O mais completo desenvolvimento da noção de campo pode ser encontrado em BOURDIEU, Pierre. As regras da arte: gênese e estrutura do campo literário. Tradução de Maria Lúcia Machado. São Paulo: Companhia das Letras, 1996, As regras da arte (BOURDIEU, 1996), para uma versão mais simplificada dessa discussão recomenda-se Os usos sociais da ciência (BOURDIEU, 2004). BOURDIEU, Pierre. Os usos sociais da ciência: por uma sociologia clínica do campo científico. Tradução de Denise Catani. São Paulo: Editora Unesp, 2004, finalmente, pPara a uma compreensão mais específica da categoria do habitus fazemos remissão ao capitulo específico ao tema, constante em BOURDIEU, Pierre. A distinção: crítica social do julgamento. Tradução de Daniela Kern e Guilherme Teixeira. São Paulo: Edusp; Porto Alegre: Zouk, 2007.A distinção (BOURDIEU, 2007).

12 BOURDIEU, Pierre. A força do direito. op. cit., p. 209. 
É exatamente a esse esforço, de contribuir para elaboração de uma ciência rigorosa do direito, que Bourdieu dedica seu ensaio. As concepções tradicionais da sociologia, hegemônicas no seu tempo, quando voltavam suas lentes para o direito, redundavam no formalismo que afirmava a independência absoluta do direito frente às outras esferas sociais ou, no extremo oposto, quando procuravam construir uma teoria crítica dessa ciência, tendiam a reduzi-la a mero instrumento de dominação a serviço das elites dominantes. ${ }^{13}$ Uma ciência rigorosa do direito, por outro lado, mantém a busca de uma perspectiva crítica, mas assume as ciências jurídicas tradicionais como parte do objeto, sem reduzir o campo a mero reflexo fotográfico das forças de produção.

Essas perspectivas dicotômicas também podem ser lidas na chave de separação entre teorias explicativas internas ou externas em relação ao campo considerado. Nas primeiras, os juristas e os historiadores do direito concebem o campo em que atuam como idealmente autônomo, sistematicamente fechado (autorreferenciado), uno e indivisível. O exemplo mais emblemático desse tipo de abordagem, segundo o próprio Bourdieu, seria A teoria pura do direito de Kelsen. Para o sociólogo francês, a teoria do jurista austríaco seria uma espécie de "limite ultra consequente" do esforço de todo um corpo dos juristas para construir um corpo de doutrinas e regras completamente independentes dos constrangimentos e das pressões sociais, tendo nele mesmo seu próprio fundamento". ${ }^{14}$

13 BOURDIEU, Pierre. A força do direito. op. cit., BOURDIEU, 1989a, pp. 209210.

14 BOURDIEU, Pierre. A força do direito. op. cit., p. 209. Segundo o próprio Kelsen, "o princípio metodológico fundamental" de uma teoria pura do Direito é libertar a ciência jurídica de todos os elementos que lhe são estranhos, para "garantir conhecimento apenas dirigido ao Direito e excluir deste conhecimento tudo quando não pertença ao seu objeto, tudo quando não se possa, rigorosamente, determinar como Direito". KELSEN, 
No extremo oposto dessas abordagens internalistas estariam os "marxistas", que enxergariam na jurisprudência apenas o "reflexo direto" das relações econômicas existentes. Nesse ponto, a metáfora do espelho e de seu reflexo aparece no texto do sociólogo para ilustrar suas críticas ao marxismo, no entanto, é utilizada de uma forma pouco criteriosa para servir como crítica genérica a toda uma tradição sociológica. Argumentamos em outra oportunidade não apenas a dívida não confessa de Bourdieu para com o marxismo, mas também que a metáfora do espelho, quando manuseadas por autores como Marx e Lukács, não pressupõe um reflexo fotográfico e nem deixa de considerar as vontades individuais dos sujeitos. ${ }^{15}$

Inserido no meio de um debate alicerçado numa falsa dicotomia, que separava as explicações internas e externas aos campos, Bourdieu defendeu que, para superar as insuficiências de ambas abordagens e, finalmente, produzir uma adequada concepção da teoria e da prática jurídica, era imprescindível levar em consideração o que ambas as perspectivas ignoram, a saber:

A existência de um universo social relativamente independente em relação às pressões externas, no interior do qual se produz e se exerce a autoridade jurídica, forma por excelência da violência simbólica legítima cujo monopólio pertence ao Estado e que se pode combinar com o exercício da força física. ${ }^{16}$

Dessa forma, as pesquisas em direito devem buscar compreender como se dão as relações e estruturas que possibilitam o exercício da autoridade jurídica no contexto brasileiro, a partir da noção de que o espaço do jurídico constitui

Hans. Teoria pura do Direito. Tradução de João Machado. $8^{a}$ ed. São Paulo: Martins Fontes, 2012p. 1.

15 CASTRO, Felipe Araújo. Bourdieu encontra Pachukanis. Revista Direito e Práxis, Ahead of the print, Rio de Janeiro, 2019, p. 11

16 BOURDIEU, Pierre. A força do direito. op. cit., 1989a p. 211. 
um universo apenas relativamente autônomo em relação às pressões externas, notadamente aquelas que advêm das forças econômicas e políticas. Nesse sentido, é imprescindível uma análise histórica que dê conta das particularidades do campo jurídico nacional, bem como entender os sentidos da violência simbólica no contexto de formação e atuação do Estado brasileiro, abrindo um flanco de interdisciplinaridade com a historiografia.

\section{Divisões e limites do trabalho jurídico}

Bourdieu passa então a se dedicar como se dá o processo de trabalho jurídico. Em síntese, defende que a aplicação do direito depende muito mais do resultado da soma das vontades individuais - política e socialmente influenciadas pelo local de fala dos sujeitos que compõe o campo jurídico - do que de uma razão universalmente válida que possa ser aprioristicamente revelada para cada caso concreto. Antes, o apelo a uma razão universal e a conformidade com precedentes de decisões anteriores serve não como razão determinante e inescapável, mas como instrumentos de racionalização que servem para dar a solução adotada ares de neutralidade e objetividade. ${ }^{17}$

Esse complexo processo de interações ocorre sem que haja, necessariamente, uma consciência finalista dos agentes individualmente considerados, assim como é independente da questão da consciência ou não acerca do resultado da soma de suas ações.

Tampouco os sujeitos do campo jurídico disputam os sentidos do direito em pé de igualdade, a despeito da retórica de se tratar de um ambiente de comunicação livre

17 AZEVEDO, Rodrigo. A força do direito e a violência das formas jurídicas. Revista de Sociologia Política, v. 19, n. 40, 2011, AZEVEDO, 2011, p. 33. 
de dominação, na qual tende a prevalecer a "força" do melhor argumento. Assim, o momento decisivo da aplicação, monopólio dos magistrados, faz com que esses agentes tendencialmente possuam maior peso sobre a determinação das normas jurídicas. E mesmo entre os seus pares os pesos são diferentes, pois aqueles juízes e juízas que, em função das suas trajetórias, tenham acumulado capitais de outras ordens - sobretudo político -, detêm poderes ainda mais significativos de submeter o campo à suas vontades.

Mesurar adequadamente as distinções decorrentes da posição singular dos magistrados, no entanto, não significa super dimensioná-las a ponto de conceder que o direito seja o que os juízes decidam que ele é. A afirmação guarda alguma verdade, pois é a sentença judicial que materializa a norma abstrata numa relação concreta, e o resultado dessa materialização é uma interpretação do magistrado. Porém, trata-se de uma atividade apenas relativamente autônoma, visto que os juízes e juízas são obrigados a utilizar um repertório específico de argumentos que são reflexivamente determinados pelo próprio campo - como as codificações, as jurisprudências e os costumes. Esse repertório, por sua vez, é constituído num complexo de relações das quais participam desde o legislador até os advogados, passando por doutrinadores e outros operadores e até mesmo os estudantes de direito. Essa dinâmica, aliás, é um elemento imprescindível para o direito ter a aparência de neutralidade e universalidade que sustenta sua legitimidade e autoridade.

No sentido contrário, esses limites reais à interpretação judicial, impostos pelas regras específicas do campo, não devem iludir ao ponto de compreender-se o momento da aplicação como fruto de uma racionalidade que independe das vontades particulares do aplicador em si, pois, dado a extraordinária elasticidade dos textos, que beiram à indeter- 
minação de conceitos como "boa vontade" e "razoabilidade", a operação hermenêutica guarda significativa margem de liberdade. Nesse sentido, destacando tanto a margem de liberdade quanto os poderes singulares dos magistrados, Bourdieu destaca:

Em resumo, o juiz, ao invés de ser sempre um simples executante que deduzisse da lei as conclusões diretamente aplicáveis ao caso particular, dispõe antes de uma parte de autonomia que constitui sem dúvida a melhor medida da sua posição na estrutura da distribuição do capital específico de autoridade jurídica. ${ }^{18}$

A dimensão dessa autonomia varia de acordo com vetores temporais e geográficos. Historicamente, os sistemas jurídicos derivados da tradição anglo-saxã, por exemplo, sobrevalorizam o momento da aplicação do direito, consequentemente, tendem a alargar os poderes dos magistrados na determinação do sentido das normas. Já os sistemas da tradição romano-germânica tendem a centrar-se na figura do legislador, além de garantirem maior prestígio aos "teóricos puros" do direito, representados pelos professores das grandes escolas jurídicas. É verdade que uma distinção forte entre as tradições venha sendo mitigada ao longo das últimas décadas, por meio de uma influência recíproca entre os dois sistemas, - ao ponto de, cada vez mais, parecer estar caminhando para uma uniformização do momento jurídico num mundo economicamente globalizado -. Ainda assim, uma unificação dos sistemas jurídicos está longe de ser completada, e as diferentes experiências continuam a guardar suas peculiaridades acerca do peso da jurisprudência na determinação do direito.

O modelo brasileiro, por sua vez, ao mesmo tempo em que foi influenciado fortemente pelas duas tradições,

18 BOURDIEU, Pierre. A força do direito, p. 222. 
mantém idiossincrasias importantes em relação a ambas as heranças. $\mathrm{O}$ fato de aqui não se ter estabelecido uma cisão rigorosa entre teóricos e práticos - sendo bastante frequente que nossos operadores jurídicos de maior prestígio (magistrados, advogados e promotores) acumulem funções de prestígio também na Academia e em postos chaves da administração estatal -, distingue substancialmente o campo jurídico nacional da realidade do Atlântico Norte.

Uma hipótese que pode ser levantada em relação a essa indiferenciação (juristas, operadores jurídicos e burocratas), somada a outras circunstâncias históricas que resultaram na preservação no tempo de uma série de privilégios da elite jurídica, contribuiu para a construção de um cenário nacional no qual os poderes dos magistrados, na determinação dos sentidos do direito, são ainda maiores quando comparados à realidade dos países altamente industrializados do Ocidente.

A confusão entre teóricos e práticos ainda pode contribuir para obstaculização de uma cultura jurídica crítica à prática forense, visto que os prático-professores (magistrados, advogados, promotores e outros que cumulam funções de magistério superior) tendem a recepcionar, agora enquanto professores, nas universidades e faculdades onde atuam, aquelas teorias que sustentam e legitimam a ampliação de poderes das suas práticas profissionais; frequentemente vistas por esses sujeitos como a principal atividade que exercem em detrimento ao magistério.

Como consequência dessa dinâmica, esses operadores professores tendem a rechaçar como "insuficientemente jurídicas", ou mesmo não científicas por que antiformalistas, justamente as posturas mais críticas à prática jurídica, aquelas com potencialidade de transformação do campo. Essa lógica é ainda mais pernóstica nas aulas de cursinhos preparatórios para concursos - muitas vezes travestidas de 
especializações -, nas quais o conteúdo reproduzido espelha o que está consolidado ou é tendência nos principais tribunais do país.

No que concerne à variação da autonomia judicial no tempo e no espaço, faz-se necessário destacar algo que deveria ser óbvio, mas que, no entanto, finda oculto na superficialidade do senso comum dos discursos jurídicos. A maior ou menor adesão dos magistrados à "letra da lei" pode constituir uma estratégia de conservação ou transformação progressista do status quo, a depender do arranjo das forças políticas consideradas em um dado momento e, sobretudo, de duas variantes fundamentais: o conteúdo das leis e o habitus dos indivíduos que ocupam a função de juiz.

É dizer, se estivermos diante uma Constituição social ampla, que garanta como direitos fundamentais os direitos humanos e uma legislação infra que construa os procedimentos e condições para efetivação dessa Carta. Uma adesão à letra da lei pela magistratura poderia ser capaz de transformar progressivamente uma sociedade desigual. Pelo contrário, no contexto de uma Constituição enxuta, garantidora de alguns poucos direitos civis e políticos, uma atividade jurisprudencial criativa, para além da letra da lei, é que poderia ser instrumento de proteção e desenvolvimento social.

Um exemplo histórico pode esclarecer nosso argumento. Ao destacar que a jurisprudência sempre fora uma questão política na Alemanha, Neumann (1996) descreve como os burocratas do judiciário, a partir do uso de interpretações enraizadas na tradição da Escola Livre do Direito (mas fora do seu contexto de origem), ajudaram a desmontar o compromisso social de Weimar de dentro do próprio Estado. ${ }^{19}$

19 No mesmo sentido, em artigo mais recente, Graver defende que o regime nacional-socialista na Alemanha contou com juízes leais que voluntariamente transformaram a ordem liberal germânica em um 
Naquela quadra histórica, a redescoberta da Escola Livre, desenvolvida no contexto do Império prussiano, defendendo uma forte autonomia judicial como ferramenta de combate aos privilégios do sistema político-jurídico autoritário então existentes, portanto, tinha um teor originário originalmente progressista, mas, anos mais tarde, serviu "a destruição de um direito positivo que já havia incorporado uma substancial reforma social" ${ }^{20} \mathrm{com}$ a Constituição de Weimar (1919). Vejamos uma parte de seu relato:

Os juízes, baseados no seu livre convencimento, sem "quebrar a lei", praticamente aboliram um grande número de leis do Código Civil, especialmente aquelas leis que beneficiavam a classe trabalhadora. Além disso, os juízes alemães a partir de 1919, ao assumirem o poder de controle judicial de constitucionalidade, constituíram-se num tipo de Upper House, em adição ao Reichtag. Qualquer lei editada pelo Parlamento podia ser revista por qualquer juiz com base na sua compatibilidade com a Constituição, apesar de nenhum juiz ter ousado fazê-lo durante o período de vigência da Constituição de Bismarck. Um grande número de leis interferindo no direito de propriedade e na liberdade de contratar foram consideradas inconstitucionais. ${ }^{21}$

De maneira análoga, durante o mais recente processo de redemocratização da esfera pública brasileira, o movimento suprapartidário em defesa de um ativismo judicial, que inicialmente animou setores da vanguarda do campo

instrumento de opressão, discriminação e genocídio, sem que fossem necessárias interferências significativas no funcionamento prévio das Cortes e sem a aplicação de medidas disciplinares contra a magistratura. GRAVER, Hans Petter. Why Adolf Hitler Spared the Judges: Judicial Opposition Against the Nazi State. German and law, v. 19, n. 4, pp. 845878, 2018.(GRAVER, 2018).

20 NEUMANN, Franz. The decay of German democracy. In: SCHEUERMAN (org.). The rule of law under siege: selected essays on Franz L. Neumann and Otto Kirchheimer. Los Angeles: University of California Press, 1996, p. 29.

21 Ibidem, p. 36. 
jurídico com apoio de parte da sociedade brasileira, apostou na efetivação dos direitos sociais positivados na Constituição Cidadã via Judiciário. Hoje essa aposta não parece empolgar tanto, especialmente, quando se considera quem são os sujeitos que concretamente ocupam as posições de maior peso no interior das elites jurídicas e como atuaram e estão atuando na atual crise política nacional.

As críticas sobre a atuação política, conservadora e moralista do Judiciário brasileiro na atual escalada da crise política, têm muitos fronts, de distintos vieses político-ideológicos: vão desde o ensaio de Lynch (2017), no qual o autor compara o que denomina "revolução judiciarista" - um movimento iniciado nas academias jurídicas pós-88, que é alavancado pelas jornadas de 2013 e toma forma mais acabada na Operação Lava-jato - como uma espécie de "tenentismo togado", no qual os agentes jurídicos acreditam estar renovando a política brasileira pela via judicial de combate a corrupção, enfrentando articulações de resistência das antigas oligarquias políticas; até interpretações de inspiração marxista, nas quais enxerga-se, nos mesmos acontecimentos, uma aliança tática entre a burguesia integrada ao capital internacional e a alta classe média (representada pelas elites jurídicas) para desmontar a hegemonia da burguesia nacional e o projeto de reformismo fraco do Partido dos Trabalhadores. ${ }^{22}$

22 BOITO JUNIOR, Armando. Lava-Jato, classe média e burocracia do Estado. Revista Lumen, v. 2, n. 3, 2017BOITO JUNIOR, 2017. A crítica é ainda muito variada e, dado o calor dos acontecimentos, ainda está em construção e muito distante de atingir um consenso. Porém, a parte dos ideólogos juristas que sustentam as atividades das elites jurídicas, nas ciências sociais e políticas, há uma tendência a enxergar o movimento "judiciarista" senão como algo negativo em si, pelo menos com potencial e tendência extremamente danosos à democracia brasileira. Nesse ponto destaca-se ainda SANTOS, Wanderley Guilherme dos. A democracia impedida: o Brasil do séc. XXI. Rio de Janeiro: FGV Editora, 2017.a obra de SANTOS (2017). 
Em suma, as possibilidades de expansão do jurídico por meio da inserção de temas políticos em suas competências, normalmente vendidas como mecanismo de controle de correção de justiça das decisões parlamentares (e/ou judiciais de primeira instância), não devem ser tomadas como algo positivo em si mesmas. Isso porque sempre representarão obstáculos e retrocessos ao progresso social quando manipuladas por sujeitos conservadores, como foi o caso da República de Weimar e hoje é o caso da atual República brasileira.

Nessa linha, sustentamos que os outputs do campo jurídico, manifestados por excelência no momento de concretização das interpretações judiciais aos casos concretos, dependem muito mais de uma relação dialética entre as motivações individuais dos operadores e as predisposições do campo jurídico do que de uma razão universal que possa ser apreendida por exercícios cognitivos de abstração. Portanto, contém muito mais de arbitrário do que os juristas estão dispostos a admitir.

No mais das vezes, esse caráter autoritário do campo jurídico é sublimado por seus sujeitos, para enxergar nesses espaços uma comunicação livre de dominação, neutra e independente; dessa forma, os juristas dignificam suas próprias atividades e seus espaços de atuação. Segundo Bourdieu, as decisões judiciais apenas podem "distinguir-se de simples atos políticos de força na medida em que se apresentam como resultado necessário de uma interpretação regulada" 23 e é assim que devem aparecer para lograr a adesão dos profissionais e a obediência passiva do restante da sociedade.

Isso significa que o direito, ainda que seja resultado de atos políticos, não pode prescindir de sua forma específica; assim, deve constituir-se enquanto um campo de disputas

23 BOURDIEU, Pierre. A força do direito. op. cit., 1989a, p. 214. 
reguladas, entre diferentes interesses, do qual supostamente emergem vitoriosos os melhores argumentos juridicamente traduzidos. Em outras palavras, o direito deve aparentar neutralidade para parecer imparcial. Essa estrutura não é simplesmente ideológica, no sentido de constituir uma falsa consciência ou mera ilusão cientificamente elaborada - como pretendem certas leituras reducionistas de inspiração marxista -, antes, trata-se de um momento determinante do funcionamento específico do sistema jurídico. Ambos os momentos do direito - o ser e o dever-ser - apresentam uma complementariedade dialética; compõe o que a melhor tradição marxista denomina duplo caráter de todo o preceito jurídico. ${ }^{24}$

A questão que precisa ser compreendida, nesse caso, é como, a partir desse aparente caos de interesses divergentes, o campo jurídico logra manter constantes no tempo determinadas características e funções. Em outras palavras, estamos afirmando que os resultados das interpretações são objetos de disputas entre diferentes agentes, porque o direito mantém uma função-atuação conservadora de manutenção das relações como estabelecidas independentemente da renovação dos seus agentes ao longo do tempo; evitando, por exemplo, que as correntes progressistas que disputam a hegemonia no seu interior venham a ter êxito.

Mais uma vez, parece-nos que a noção de habitus é capaz de começar a responder a essas perguntas. Ainda sobre o campo jurídico, Bourdieu expõe:

É pois um campo que, pelo menos em período de equilíbrio, tende a funcionar como um aparelho na medida em que a coesão dos habitus espontaneamente orquestrados dos intérpretes é aumentada pela disciplina de um corpo hierarquizado o qual põe

24 SARTORI, Vitor Bartoletti. Lukács e a crítica ontológica do Direito. São Paulo: Editora Cortez, 2010, SARTORI, 2010, p. 104. 
em prática procedimentos codificados de resolução de conflitos entre profissionais da resolução regulada de conflitos. ${ }^{25}$

O autor destaca que em função da coesão espontaneamente orquestrada do habitus, o campo jurídico tende a funcionar como um aparelho estatal, no sentido que lhe dava o estruturalismo althusseriano, pois não apenas tende a exercer uma função importante de conservação do status quo em benefício do Estado e das elites dominantes, como também, por meio da construção de um complexo sistema de hierarquias e burocracias, apresenta-se rígido às mudanças que poderiam ser produzidas internamente por seus próprios agentes. Precisamos analisar mais de perto essa afirmação.

A coesão dos habitus é garantida pelo compartilhamento dos espaços de formação e socialização dos indivíduos. No Brasil, a esmagadora maioria dos magistrados provém de núcleos familiares com alta renda, tendo frequentado os melhores colégios privados de suas respectivas cidades - não raramente, escolas católicas, que, porém, atualmente estão sendo substituídas por instituições de aprendizagem técnica distantes de compromissos pedagógicos em seu sentido tradicional. Essa educação de qualidade, muito superior às demais - especialmente em relação ao ensino público ${ }^{26}$-,

25 BOURDIEU, Pierre. A força do direito. op. cit., p. 214.

26 No resultado do Exame Nacional do Ensino Médio (ENEM) de 2015, prova aplicada para aferir a qualidade do ensino médio e dar acesso às universidades e faculdades que aplicam o Sistema de Seleção unificada (SISU), dentre as cem melhores notas, apenas três forma obtidas por escolas públicas - todas as três integrantes da rede federal de ensino. Isso considerando que, naquele ano, $85 \%$ das matrículas desse nível de ensino eram de escolas públicas. Disponível em: https://jornal.usp.br/ atualidades/resultados-do-enem-aprofundam-diferencas-entre-escolaspublicas-e-privadas-diz-especialista/. Acesso em 23 de janeiro de 2018. Ainda sobre o ENEM 2015, para Francisco Soares, ex-presidente do INEP (Instituto Nacional de Estudos e Pesquisa Educacionais Anísio Teixeira), “Entre as melhores classificadas, um primeiro fato a considerar é que 
apenas pode ser arcada pelas famílias com mais alto poder aquisitivo e garante para seus herdeiros uma vantagem competitiva praticamente insuperável na disputa pelo acesso aos concorridos cursos federais superiores.

A política de acesso às instituições de ensino superior públicas, mediante a reserva de $50 \%$ das vagas para os alunos provenientes de escolas públicas, denominada "política de cotas", procurou subverter exatamente esse privilégio: a concentração da educação superior de qualidade nos círculos das elites brasileiras. Não obstante os seus eventuais equívocos de aplicação, seus principais críticos se levantam contra o suposto desrespeito ao princípio da meritocracia da seleção em prova pública, convenientemente esquecendo-se que o caminho dos indivíduos até o momento dessa seleção é marcado por profundas desigualdades.

Porém, a simples inserção de novos sujeitos, antes excluídos do campo judicial, como mulheres, negros, população LGBTQI, etc., per si, não é capaz de modificar o funcionamento das relações de poder no interior das instituições jurídicas, visto que, para além da tendência de uma coesão prévia de narrativas, resta ainda a manifestação das instituições como "estruturas estruturadas", isto é, estruturas que contam com uma hierarquia profissional e de comportamentos preexistentes ao ingresso dos sujeitos individualmente considerados na instituição. Essa é uma estratégia de "correção" dos habitus desviantes, pois a não adequação aos valores já compartilhados na instituição pode levar a

as privadas selecionam primeiro seus alunos pela renda e também pelo desempenho em provas. Esta seleção é frequentemente feita ao longo dos anos, convidando os estudantes mais fracos a saírem. As escolas públicas que estão nas melhores colocações são também aquelas que admitem seus alunos através de difíceis vestibulares". Disponível em: https://g1.globo. com/educacao/noticia/das-100-escolas-com-maior-nota-media-no-enem2015-97-sao-privadas.ghtml. Acesso em 11de abril de 2019. 
dificuldades na progressão dentro da carreira e outros tipos de punições menos visíveis.

Em função dessas características, sobretudo a homogeneidade dos habitus, é que o campo jurídico, apesar de sua aparência de uma disputa justa e regulada, tende a funcionar como um aparelho. O termo faz remissão à gramática estruturalista althusseriana, tão criticada pelo autor. Em suma, é uma espécie de paradoxo reconhecidamente presente na obra de Bourdieu, a saber, apesar de o autor defender que o campo jurídico não seja um mero reflexo fotográfico da base econômica, esse espaço acaba funcionado de maneira muito próxima da descrição dos aparelhos em função de como os campos jurídicos se constituíram historicamente em relação aos campos estatais.

No entanto, isso não significa que a teoria dos campos seja uma maneira mais complexa e desnecessariamente complicada de descrever o mesmo fenômeno. Há nesse aspecto uma sutil, mas importante diferença: afirmar que o campo jurídico tende a funcionar como um aparelho não é o mesmo que afirmar que ele necessariamente funciona como um. No mínimo, persiste a possibilidade que ele venha a atuar de outra forma, que é exatamente o que mais nos interessa. No caso, se é exatamente a homogeneidade dos habitus que aproxima o funcionamento do campo jurídico àquele de um aparelho, consequentemente, investigar as possibilidades de modificação desses habitus seria inquirir sobre as possibilidades de transformação do próprio campo.

No sentido contrário, qualquer aspiração à transformação que tenha por estratégia modificações nas estruturas do campo jurídico, mas que mantenha intactas as estratégias de reprodução dos sujeitos que historicamente exerceram as funções de elite no seu interior, e a exercem até hoje, está fadada não apenas ao fracasso, mas a retroalimentar a 
legitimidade do seu funcionamento por meio da venda de falsas esperanças.

As diferentes dimensões da divisão do trabalho jurídico, entre dentro e fora, teóricos e práticos, dominantes e dominados, garantem essa aparência técnica da neutralidade, ao mesmo tempo que sustentam a eficácia do poder jurídico enquanto poder simbólico. Ou seja, prescindindo na maioria das vezes da violência física. Cada uma dessas diferentes divisões do trabalho jurídico precisa ser adequadamente recortada e rigorosamente observada - por meio de etnografias, observações participantes, censos, entrevistas semi-estruturadas, prosopografias etc. -, com o objetivo de atingir uma melhor compreensão do campo jurídico nacional.

No que concerne à primeira e mais fundamental divisão, aquela que separa leigos e profanos, referente às barreiras de entrada oficial no campo jurídico e judicial, é preciso aprofundar as pesquisas acerca das condições de entrada nas faculdades de direito (diferenciando-as entre público e privada, tradicionais e emergentes) e o acesso aos cursinhos preparatórios para as carreiras jurídicas, bem como o funcionamento cotidiano dessas instituições de ensino.

Quanto à separação entre teóricos e práticos, ela é muito mais opaca que a anterior, visto que muitos profissionais sustentam ambas as posições, especialmente no contexto brasileiro. Com efeito, o caso nacional difere sensivelmente dos contextos analisados por Bourdieu em A força do Direito os casos da tradição jurídica alemã, francesa e estadunidense -, justamente porque não há por aqui uma distinção mais rigorosa entre teóricos e práticos.

O desprestígio dos teóricos puros, aliás, é notável na recorrente réplica da sociedade à declaração da condição de professor de direito: "só professor?"; uma pergunta interposta na expectativa do exercício de alguma outra atividade 
de operador do direito, essa sim, suficientemente digna de dedicação exclusiva. Evidentemente, nem todo o exercício de uma atividade prática no campo jurídico significa uma condição de prestígio, sobretudo após a massificação da advocacia que teve como um de seus resultados a proletarização de muitos advogados, principalmente aqueles formados fora dos grandes centros jurídicos e/ou carentes de capital social e econômico no início de suas carreiras.

Acerca de nossa práxis, as dificuldades de desenvolvimento de uma cultura jurídica própria, ${ }^{27}$ somada a importações frequentemente mal adaptadas e subservientes das principais tradições citadas por Bourdieu [romano-germânica e anglo-americana], bem como o fato do campo jurídico nacional ter as costas dadas às tradições de nossos vizinhos do sul ${ }^{28}$, resultam em um sincretismo metodológico marcante na nossa interpretação judicial ${ }^{29}$ que, geralmente, funciona como estratégia de mascaramento de decisões subjetivistas. ${ }^{30}$ Cada um desses aspectos demanda maiores

27 MATOS, Andytias Soares de Moura Costa; RAMOS, Marcelo Maciel. A cultura jurídica brasileira: da exceção à atual promessa de emancipação. Quaestio Iuris, v. 9, n. 1, pp. 376-404, 2016.

28 BRANDÃO, Pedro. O novo constitucionalismo pluralista latinoamericano. Rio de Janeiro: Lumen Juris, 2015BRANDÃO, 2015.

29 Virgílio Afonso da Silva crítica as importações acríticas do direito constitucional brasileiro, destacando a posição que o direito constitucional alemão ocupa no imaginário de nossos juristas, destacando justamente a ausência de método de nossos intérpretes. "Não é difícil perceber que a doutrina jurídica recebe de forma muitas vezes pouco ponderada as teorias desenvolvidas no exterior. E, nesse cenário, a doutrina alemã parece gozar de uma posição privilegiada, já que, por razões desconhecidas, tudo o que é produzido na literatura jurídica germânica parece ser encarado como revestido de uma aura de cientificidade e verdade indiscutíveis" DA SILVA, Virgílio Afonso. Interpretação constitucional e sincretismo metodológico. In: Virgílio Afonso da silva (Org.), Interpretação constitucional. São Paulo: Malheiros, 2005, p. 116.

30 Marcelo Neves (2013, p. ix), por sua vez, ao tratar sobre a recepção do debate acerca de princípios e regras e sobre a constitucionalização do direito, 
aprofundamentos no campo da sociologia jurídica.

Por fim, ainda sobre as divisões do trabalho jurídico, há a cisão entre aqueles que desenvolvem atividades de uma mesma natureza, uma diferenciação que separa os dominantes e dominados das respectivas frações de classe. Não se pode ignorar, por exemplo, que os interesses e capacidades dos juízes substitutos - função de entrada na carreira - certamente não são os mesmos daqueles que compõem a elite do judiciário, assim como suas estratégias de inserção e disputa no campo:

Com efeito, o conteúdo prático da lei que se revela no veredicto é o resultado de uma luta simbólica entre os profissionais dotados de competências técnicas e sociais desiguais, portanto, capazes de mobilizar, embora de modo desigual, os meios ou recursos jurídicos disponíveis, pela exploração das regras possíveis, e de utilizar eficazmente, quer dizer, com armas simbólicas, para fazerem triunfar a sua causa. ${ }^{31}$

É essa lógica paradoxal de uma divisão do trabalho, que se dá fora de qualquer desejo consciente, o verdadeiro princípio de legitimidade do direito, passível de revelação pela observância de determinados métodos rigorosos de interpretação sociológica. Esse processo de racionalização da divisão do trabalho se desenvolve em um espaço de concorrência de interpretações e vontades, porém, trata-se de um espaço reduzido de possibilidades pela homogeneidade dos

mais uma vez, fortemente influenciado pela doutrina alemã, constatou nos ides dos nos 2000 que "salvo algumas exceções, tratava-se mais uma vez, de importação acrítica de construções teóricas e dogmáticas, sem o crivo seletivo de uma recepção jurídico-constitucionalmente apropriada [...] a retórica principialista servia ao afastamento de regras claras e completas, para encobrir decisões orientadas à satisfação de interesses particulares". NEVES, Marcelo. Entre Hidra e Hércules: princípios e regras constitucionais. São Paulo: Martins Fontes, 2013, p. ix.

31 BOURDIEU, 1989a,Pierre. A força do direito. op. cit., p. 224. 
habitus dos agentes envolvidos e o peso desigual exercido pelas frações dominantes da elite jurídica. ${ }^{32}$

Estamos convencidos que a prática dos agentes jurídicos deve muito mais às afinidades de visão de mundo, que conectam fortemente os operadores jurídicos aos detentores dos poderes temporais, sobretudo os poderes econômicos e políticos, do que a uma razão apriorística que possa ser deduzida pelo raciocínio jurídico a partir da vontade da lei, dos legisladores ou de uma dada comunidade. As relações entre as elites jurídicas, notadamente dos magistrados, com as demais elites do poder são marcadas por fortes interseções, que são específicas de cada contexto temporal e geográfico e influenciam significativamente o momento jurídico.

\section{O poder de nomeação: magia, crença e limites}

No que consiste exatamente esse poder da linguagem jurídica que intervém na realidade objetiva, criando ou fazendo desaparecer situações de fato? Quais os paralelos históricos desse tipo de ferramenta?

Não ocasionalmente, Bourdieu compara o poder simbólico contido nos atos estatais com aqueles da magia. Utiliza essa comparação para dar a entender que "o fato do Estado conseguir impor-se tão facilmente" constitui uma virtude quase mágica que decorre do fato do aparelho estatal estar em condições de produzir as estruturas cognitivas sobre as quais é pensado. ${ }^{33}$ Esses atos são mágicos no sentido de constituírem ilusões eficientes, pelo fato de produzirem efeitos concretos sem a aplicação aparente de qualquer força externa, são atos que valem por si e contam com uma obediência generalizada daqueles a quem são dirigidos.

32 Ibidem, p. 225.

33 BOURDIEU, 2014Pierre. Sobre o Estado. op. cit.,, pp. 391 e ss. 
A investidura de um sujeito na função de magistrado é um importante exemplo dos atos de nomeação. Em um "passe de mágica", esse ato é capaz de dotar de poderes excepcionais o indivíduo consagrado pelo processo de seleção, consolidando, legitimando e encobrindo contextos de profunda desigualdades, nos quais são frequentemente beneficiados os indivíduos que logram a aprovação nos concursos públicos; tudo isso sem o recurso a nenhuma violência aparente. A condição de juiz ou juíza projeta sobre sujeitos concretos uma série de características morais, como honradez, eficiência, imparcialidade política etc., traços que compõem o imaginário de como a sociedade enxerga os magistrados e como os magistrados enxergam a si mesmos; e isso independentemente do aprovado ser um jovem recém-formado sem qualquer experiência profissional com propensões conservadoras e antirrepublicanas ou não. ${ }^{34}$ Ainda segundo Bourdieu, a "magia social" efetivamente transforma o agente, fazendo com que ele (re)conheça a si mesmo e seja (re)conhecido pelos demais como outra coisa que não era anteriormente, destacando ainda a importância de outros ritos para a construção dessa nova realidade, desde a publicação em jornais oficiais às investiduras públicas.

Para que isso aconteça, é fundamental a crença daqueles a quem os atos estatais são destinados. Com efeito, é necessário que os indivíduos sob o julgo estatal creiam na capacidade do Estado de criar a ordem social e na justeza desse procedimento; de maneira análoga ao mágico que depende do conjunto de relações no qual está inserido e lhe atribui a capacidade de fazer "mágica". ${ }^{35}$

Como já foi dito, o direito contribui decisivamente para esse quadro por meio do poder de nomeação de que é

34 BOURDIEU, Pierre. La nobleza del Estado. op. cit., p. 169.

35 BOURDIEU, Pierre. Sobre o Estado, 
investido pelo próprio Estado. ${ }^{36}$ É por meio dos processos do campo jurídico que se efetiva essa "mágica", consubstanciada no "poder simbólico que cria as coisas nomeadas" ${ }^{37}$ Inversamente do que poderia se supor, ainda que seja ele quem garanta os aparelhos que lhe sustentam, o Estado não pode prescindir dessa estratégia de que se utiliza para exercer seu poder simbólico, que é justamente o direito. Dessa relação dialética de codependência é que surgem as autonomias relativas entre o campo da política e do direito e entre esses e o campo da economia. É importante notar que, sobretudo considerando o contexto brasileiro, no qual as eleições são predominantemente definidas pelo poder econômico, as análises marxistas que apontam a economia como momento preponderante da realidade social se aproximam demasiadamente da realidade objetiva.

De certa forma, o discurso jurídico é um tipo de linguagem que encerra disputas pontuais sobre determinadas questões. Como a história não se constrói apenas sobre fatos, mas também sobre versões e narrativas acerca desses fatos e algumas disputas parecem não encontrar termo por meio do diálogo direto entre as partes envolvidas -, a linguagem jurídica transforma estas partes em clientes e desloca a sua disputa para um espaço técnico, no qual apenas os juristas estão autorizados a intervir, alguns representando seus respectivos clientes e outros os aparelhos estatais competentes à questão. $\mathrm{O}$ Estado conta com o monopólio do uso da violência simbólica para apresentar a resolução desses conflitos que são postos diante de seus aparelhos jurídicos, ele então expressa esse poder simbólico pela capacidade de determinar um ponto de vista parcial como sendo universal e justo. Esse processo tem sua conclusão e clímax na atuação autorizada do magistrado que, caso não obedecida, pode ser

36 BOURDIEU, Pierre. A força do direito. Op. Cit.,

37 Ididem, p. 142. 
imposta pelas forças policiais - ou militares, considerando-se o atual contexto nacional.

Porém, afirmar que o direito possui esse poder de nomeação e efetivamente é capaz de, em alguma medida, construir e transformar o mundo social, não significa conceber que esse poder seja independente ou ilimitado em relação ao próprio contexto social no qual o direito está inserido. Assim, ainda que seja correto afirmar que o direito "faz o mundo social", a afirmação apenas se sustenta se tivermos em mente também "que ele é feito por esse [mundo social]". ${ }^{38}$

Como bem lembra Neumann, apoiado, por sua vez, no que consideramos ser a melhor tradição da sociologia marxista, ${ }^{39}$ a norma jurídica ordena a realidade social, mas não sobre quaisquer circunstâncias, visto que também o direito é fortemente influenciado pela subestrutura social, que não está, de maneira alguma, reduzida à esfera econômica. Segundo o autor, trata-se mesmo de uma vulgaridade tautológica afirmar que mudanças no sistema jurídico, bem como nas práticas de interpretação judicial, tenham a potência de acarretar mudanças sociais. Nesse caso, mais importante que aceitar a realidade dessa afirmação é compreender como se dá esse processo e quais são os seus limites, visto que "não podemos nos esquecer que uma mudança no sistema jurídico será efetuada apenas se uma tal mudança é demandada por forças sociais" ${ }^{40}$ Essa nos parece ser a principal função da sociologia jurídica.

38 BOURDIEU, Pierre. A força do direito. op. cit., 1989a, p. 237.

39 Nas passagens aqui consideradas são citados Paschukanis, Engels e o próprio Marx. NEUMANN, Franz. O império do direito: teoria política e sistema jurídico na sociedade moderna. Tradução de Rúrion Soares Melo. São Paulo: Quartier Latin, 2013, pp. 54 e ss.

40 Como exemplo dessa dinâmica, o autor alemão diz que certamente uma mudança no código civil no sentido da abolição da propriedade afetaria o sistema econômico das propriedades, porém, tal mudança apenas pode 
Esse é o primeiro limite importante do direito, que ainda hoje parece ser ignorado pelas suas teorias formalistas: o poder de nomear, frequentemente, só é capaz de garantir a existência daquilo que de alguma maneira esteja latente na sociedade. É o caso, por exemplo, da abolição formal da escravatura no Brasil, que apenas pôde ser declarada oficialmente, na forma do direito, em maio de 1888, quase setenta anos após a independência brasileira e cem anos da declaração universal dos direitos do homem da Revolução Francesa. Foi necessário esse longo lapso temporal, no qual diversos fatores foram gradativamente minando as bases de sustentação do regime escravocrata - desde as lutas de resistências dos negros organizados em quilombolas, passando pelo avanço do discurso abolicionista sobre as esferas culturais, até a diversificação da economia produtiva ao ponto em que prescindisse da mão de obra escrava -, para que finalmente adviesse a Lei Áurea como reconhecimento do que já estava dado. ${ }^{41}$

ser efetivamente esperada, no sentido dado por Bloch de ser um utopia concreta, caso as forças políticas e sociais convirjam nessa direção. Nesse sentido "uma mudança social importante do sistema jurídico não acontece repentinamente: isto é um produto de um processo social". (NEUMANN, 2013, Ibidem, p. 59).

41 Para um panorama geral dos últimos anos da escravidão ver CHALHOUB, Sidney. Visões da liberdade: uma história das últimas décadas da escravidão na corte. São Paulo: Companhia das Letras, 1990, Chalhoub (1990). Ppara as lutas de resistência negra ver MACHADO, Maria Helena P. Toledo. Teremos grandes desastres se não houver providências enérgicas e imediatas: a rebeldia dos escravos e a Abolição da escravidão. In: GRINBERG, Keila e SALLES, Ricardo. (Orgs.). O Brasil imperial. V.3. Rio de Janeiro: Civilização Brasileira, 2009Machado (2009) e SILVA, Eduardo. As camélias do quilombo do Leblon: uma investigação de história cultural. São Paulo: Companhia das Letras, 2003. Silva (2003). Por fim, para uma história geral das escravidões no Brasil, desde os tempos coloniais às permanências após a abolição formal, ver GOMES, Flávio dos Santos; SCHWARCZ, Lília Moritz. (Orgs.). Dicionário da escravidão e liberdade: 50 textos críticos. São Paulo: Companhia das Letras, 2018.Gomes; Schwarcz (2018) 
Não obstante essa perspectiva historiográfica dialética ser um lugar comum nas ciências sociais brasileiras, por meio da disseminação de métodos de exposição e pesquisa que conectam numa relação de interdependência a história do direito e o desenvolvimento dos demais campos sociais, paradoxalmente, no campo do ensino jurídico ainda persistem as narrativas formalistas que enxergam o desenvolvimento do direito como um processo autônomo de evolução de suas categorias internas.

Esse tipo de educação, desconectada da realidade histórico-social na qual está inserida, favorece a emergência no habitus dos operadores jurídicos, não raras vezes bem intencionada, de uma arrogância intelectual expressa por meio da crença na possibilidade de transformação da realidade por meio da elaboração e aplicação de novas leis, alegadamente melhores que as anteriores. Essa arrogância, sustentada em pressupostos falsos, mas com consequências reais, é cultivada historicamente nos cursos de direito e ainda está fortemente presente em nossos operadores jurídicos.

Nossa hipótese é que esse tipo de visão de mundo constitui o habitus dominante e hegemônico do campo jurídico nacional, capaz de produzir estruturas mentais que acreditam ter posto fim à violência contra mulher com a edição da Lei Maria da Penha, assim como deram fim ao trabalho escravo no Brasil com a edição da Lei Áurea; que acreditam combater a criminalidade pela edição de novos e mais severos tipos penais, que creem combater a corrupção com mais dez novas medidas autoritárias de investigação e assim por diante; os exemplos são infindáveis.

Nesse campo afloram as possibilidades de pesquisas centradas em metodologias capazes de demonstrar as contradições entre o que pensam (ou declaram pensar) e como agem nossos operadores jurídicos, seja por meio de análises 
dos discursos presentes nas peças jurídicas ou por meio de entrevistas e questionários verticalizados, associados a pesquisas quantitativas como os censos produzidos pelo CNJ e FGV e revisitação da historiografia sobre as elites jurídicas.

Em suma, o que a abordagem formalista da educação jurídica ignora é uma máxima antiguíssima da filosofia, remontada várias vezes ao longo da história, enfatizada na contemporaneidade por Bourdieu, qual seja: "não se transforma a sociedade por decreto" ${ }^{42}$ Pois o poder de nomear, pode acelerar ou atrasar, mas só faz advir o que anuncia porque anuncia aquilo que está em vias de surgir. ${ }^{43}$

Dessa assertiva, no entanto, não se deve concluir o extremo oposto, ou seja, que o poder de nomear seja inútil, na medida que se prestaria unicamente a confirmar o já existente. Pois ainda que relativizado, o poder de nomear tão pouco deve ser desconsiderado, tendo em vista que:

Ao concederem às realidades e às virtualidades históricas o pleno reconhecimento que a proclamação profética encerra, oferecem-lhe, pelo efeito de licitação, e até mesmo de consagração, associado à publicação e a oficialização, a possibilidade real de aceder a existência plena, quer dizer, conhecida e reconhecida, oficial. ${ }^{44}$

Retornando ao nosso exemplo sobre a escravidão, não significa que, porque o fim do modelo escravocrata estava prestes a se consumar na realidade objetiva e pronto para ser recebido pelo espírito da sociedade brasileira, a Lei Áurea tenha sido inútil ou tenha sido desnecessária. A norma elevou o status da abolição à condição de ato oficial reconhecido pelo Estado, possibilitando, em potência, que seus últimos resquícios fossem combatidos por meio dos aparelhos es-

42 BOURDIEU, Pierre. A força do direito. op. cit., p. 239.

43 BOURDIEU, 1989a, Ibidem, pp. 238 e ss.

44 BOURDIEU, 1989a, Ibidem, p. 239. 
tatais, além de passar a gozar do mesmo prestígio dos atos estatais mágicos que, em princípio, não podem sequer ter sua existência questionada. No mesmo sentido, a Lei Maria da Penha, ainda que não resolva de maneira cabal a cultura da violência contra a mulher, é um passo importante de deslocamento das disputas sobre o tema para dentro do campo do poder. ${ }^{45}$

Dessa forma, as lutas sociais e políticas não devem prescindir do direito, mas estar atentas aos limites inerentes de seu funcionamento conservador. É importante notar ainda, que os limites do poder de nomeação exercido pelo direito, influenciados pelas conexões entre esse campo e as demais esferas sociais, tendem sempre a serem alargados nos momentos de convulsão social que precedem revoluções, grandes mudanças políticas e sociais. Nessas oportunidades as margens do que se pode (re)nomear ou criar, por meio da linguajem jurídica, são acrescidas as possibilidades efetivas de transformação social, expressas nas forças políticas e sociais. No entanto, esse poder sempre dependerá, em larga medida, dos habitus concretos dos indivíduos que vestem as togas. Não raramente, como no já mencionado caso do desmonte da República de Weimar, os poderes jurídicos de nomeação foram utilizados para manter os privilégios das elites dominantes com quem se identificavam os magistrados.

45 A pesquisa de Rodrigo Azevedo (2011) aponta no mesmo sentido, ao afirmar que a comunidade jurídica e o Poder Judiciário em particular podem, em dadas circunstâncias, responder às demandas que provêem de setores sociais menos favorecidos. Nesse ponto, o reconhecimento formal de certas posições jurídicas, associado à mobilização social e política, tem a possibilidade de servir como balizas para conformação progressiva do campo jurídico, mesmo que a contragosto dos seus operadores. AZEVEDO, Rogrido G. A força do direito e a violência das formas jurídicas. Revista de Sociologia Política, v. 19, n. 40, 2011. 
Da mesma maneira, o atual desmonte do Estado social brasileiro, muito provavelmente, contará com a aquiescência dos operadores jurídicos, manifestadas em interpretações favoráveis às reformas, mesmo quando flagrantemente inconstitucionais, ou desfrutará da omissão do Supremo Tribunal Federal no enfrentamento das políticas de austeridade fiscal, que são questionadas por inúmeras ações dos partidos políticos e outros legitimados. É importante lembrar que não há regra formal específica, no regulamento da Corte Suprema, sobre a ordem e o tempo da entrada em pauta das ações que lhe são propostas; tarefa que cabe à discricionariedade do presidente em exercício. Assim, ao optar por espetacularizar suas competências penais em julgamentos midiáticos, em detrimento do enfretamento da constitucionalidade das medidas de austeridade fiscal, o Tribunal, por omissão, legitima tais políticas.

Já em tempos de normalidade institucional sobressaem os limites impostos pela lógica dos precedentes, que é inerente ao campo jurídico e liga irremediavelmente o presente ao passado, limitando o espaço dos possíveis. Toda sociedade que logra obter alguma estabilidade temporal desenvolve estratégias de conservação das posições sociais. Nas sociedades modernas, a lógica marcante de conservação dessas relações desiguais é expressa, em grande medida, pelos usos do direito. A dinâmica do campo jurídico em tempos de estabilidade - ou seja, excetuando eventuais momentos revolucionários que venham questionar os fundamentos mesmos da ordem jurídica - é capaz de garantir que

o porvir será a imagem do passado e de que as transformações e as adaptações inevitáveis serão pensadas e ditas na linguagem da conformidade com o passado. ${ }^{46}$

46 BOURDIEU, Pierre, 1989a, p. 245 
Nessa passagem, o tom das descrições específicas sobre o campo jurídico e seu funcionamento aproximam Bourdieu de certas correntes marxistas, em que pese seus esforços para distanciar-se dessa tradição. No entanto, no clássico enxerto O conceito do esclarecimento, de 1944, Adorno e Horkheimer, ao apresentarem a ciência como uma espécie de substituta do mito, descrevem, de maneira muito aproximada a que Bourdieu expressará décadas mais tarde, que:

A subsunção factual, seja sob a pré-história lendária, mítica, seja sob o formalismo matemático, o relacionamento simbólico do presente ao evento mítico no rito ou à categoria abstrata na ciência, faz com que o novo apareça como algo predeterminado, que é assim na verdade o antigo. ${ }^{47}$

$\mathrm{O}$ que os autores ligados ao que mais tarde ficaria conhecida como a escola de Frankfurt defendem é que a tentativa de compreensão do factual, da realidade objetiva, seja pelos métodos antigos da experiência mítica, seja pelas categorias abstratas das ciências hegemônicas contemporâneas [as ciências tradicionais], tem por consequência extinguir as possibilidades de transformação do social, na medida em que o futuro está fadado a ser uma repetição do passado.

No que concerne especificamente ao campo jurídico, as ciências tradicionais de que falam Adorno e Horkheimer, vinculadas à lógica formal da cognição a priori e, em certa medida, consequência da expansão dos cânones dos modelos matemáticos também às ciências do espírito, são representadas exatamente pelas ditas teorias puras do direito descritas por Bourdieu no início do seu ensaio A força do Direito.

Assim, antes de negar essa tradição, a teoria sociológica bourdieusiana, por meio de outra gramática, parece

47 ADORNO, Theodor; HORKHEIMER, Max. Dialética do esclarecimento: fragmentos filosóficos. Tradução de Guido de Almeida. Rio de Janeiro: Zahar, 1985, ADORNO; HORKHEIMER, 1985, p. 35. 
confirmar alguns dos seus principais diagnósticos, com a vantagem de abdicar às abordagens das grandes teorias e inserir a pesquisa empírica setorial como instrumento de apreensão do real - seja no campo da educação, do direito ou do Estado. A relação entre o marxismo e a sociologia relacional bourdieusiana ainda precisa ser melhor explorada e é capaz de inserir o resultado das pesquisas empíricas no direito em um quadro mais amplo que articule dialeticamente materialismo e totalidade.

\section{Conclusão}

Apesar de não ter dedicada uma obra específica ao campo jurídico e seus agentes, como fizera em relação ao campo da arte (literatura), da educação ou da comunicação, a forma jurídica e sua relação com as demais esferas culturais não deixou de ser um tema central da obra de Pierre Bourdieu, perpassando seus principais escritos sobre o Estado e a reprodução de suas elites burocráticas.

Com efeito, as normas jurídicas e as decisões judiciais foram consideradas por Bourdieu a forma mais acabada de manifestação do poder simbólico, tendo sido instrumentos essenciais na construção do Estado moderno, com sua consequente monopolização e naturalização dos usos da violência.

As considerações feitas pelo sociólogo francês acerca do momento jurídico em $A$ força do Direito - notadamente sobre (i) as possibilidades de construção de uma ciência rigorosa do direito, (ii) as divisões do trabalho internas ao campo e (iii) o poder de nomeação que resulta dos conflitos ali travados -, desde que lidas a partir do marco da sociologia relacional e aplicadas em deferência às particularidades concretas de contextos específicos, podem servir como uma espécie de roteiro de pesquisa para desenvolvimento de uma rigorosa 
sociologia do direito no Brasil; capaz de desvelar as relações de dominação que determinam a elaboração e aplicação do direito.

O desencobrimento das relações de poder do campo jurídico nacional - com a reconstrução da participação dos juristas na gênese de um Estado nacional autoritário, a demonstração da manutenção no tempo de uma reprodução aristocrática de seus quadros e a forte tendência de um funcionamento conservador e deferente às relações de poder como desigualmente estabelecidas - não tem por consequência necessária um niilismo em relação ao momento jurídico. Antes, representa o primeiro passo na investigação das possibilidades concretas de sua transformação, ou da construção de mecanismos sociais de conformação da prática jurídica aos ditames constitucionais.

Para ampliação e consolidação de uma sociologia do direito à altura de tais objetivos, capaz de superar dialeticamente os reducionismos das teorias formalistas (internas) e instrumentalistas (externas) do Direito, nos parece fundamental que as principais hipóteses levantadas por Bourdieu em $A$ força do direito sejam retrabalhadas, de acordo com o contexto local e atual.

Nessa direção, é imprescindível o desenvolvimento e ampla publicização de pesquisas empíricas, realizadas a partir de diferentes metodologias complementares, que levem em consideração as diferentes divisões do trabalho jurídico no Brasil, entre leigos e profanos, teóricos e práticos, dominantes e dominados, etc., como condição para emergência de uma adequada compreensão dos diferentes interesses e habitus (corporativos e individuais), que incidem sobre o campo e influenciam seus resultados práticos.

Por fim, no processo de desencantamento do direito, é necessário enfrentar também o problema das expressões 
oficiais da linguagem jurídica, agora diante do conhecimento acerca das relações de dominação em que essa linguagem se manifesta. Nesse ponto, tem especial importância o desenvolvimento de pesquisas no campo da linguística, capazes de expor as contradições entre os discursos e falas jurídicas, entre os resultados objetivos da prática forense e seus objetivos declarados.

Pelo exposto, concluímos que os recursos da sociologia relacional, como trabalhados por Pierre Bourdieu ao longo de sua obra, são essenciais para realização de uma sociologia jurídica capaz de revelar o funcionamento concreto do momento jurídico e, a partir daí, de fornecer elementos para uma teoria da ação que busque, sem utopismos formais, a transformação do campo em prol da redução das desigualdades sociais - ou, pelo menos, uma práxis que supere os obstáculos impostos pelo campo jurídico à realização dessa meta.

\section{Referências}

ADORNO, Theodor; HORKHEIMER, Max. Dialética do esclarecimento: fragmentos filosóficos. Tradução de Guido de Almeida. Rio de Janeiro: Zahar, 1985.

ALMEIDA, Frederico de. Intelectuais e reforma do Judiciário: os especialistas em direito processual e as reformas da Justiça no Brasil. Revista Brasileira de Ciência Política, n. 17, 2015.

. Os juristas e a política no Brasil: permanências e reposicionamentos. Lua Nova, n. 97, pp. 213-250, 2016.

AZEVEDO, Rogrido G. A força do direito e a violência das formas jurídicas. Revista de Sociologia Política, v. 19, n. 40, 2011. 
BOITO JUNIOR, Armando. Lava-Jato, classe média e burocracia do Estado. Revista Lumen, v. 2, n. 3, 2017.

BOURDIEU, Pierre. A distinção: crítica social do julgamento. Tradução de Daniela Kern e Guilherme Teixeira. São Paulo: Edusp; Porto Alegre: Zouk, 2007.

A força do direito: elementos para uma sociologia do campo jurídico. In: Pierre Bourdieu. O poder simbólico. Tradução de Fernando Tomaz. Rio de Janeiro: Bertrand Brasil, 1989a.

As regras da arte: gênese e estrutura do campo literário. Tradução de Maria Lúcia Machado. São Paulo: Companhia das Letras, 1996.

. Esboço para uma auto-análise. Tradução de Victor Souza. Lisboa: Edições 70, 2005.

. La nobleza del Estado: educación de elite y espíritu de cuerpo. Traduzido para o espanhol por Alicia Gutiérrez. Buenos Aires: Siglo Veintinuo, 2013.

. Espaço social e gênese das classes. In: Pierre Bourdieu. O poder simbólico. Tradução de Fernando Tomaz. Rio de Janeiro: Bertrand Brasil, 1989b.

. Os usos sociais da ciência: por uma sociologia clínica do campo científico. Tradução de Denise Catani. São Paulo: Editora Unesp, 2004.

. Sobre o Estado: cursos no Collège de France (19891992). Tradução de Rosa D’Aguiar. São Paulo: Companhia das Letras, 2014.

BRANDÃO, Pedro. O novo constitucionalismo pluralista latino-americano. Rio de Janeiro: Lumen Juris, 2015.

CARLES, Pierre. La sociologie est um Sport de combat. França: C. F. Productions; V. F. Productions, 2001. 
CASTRO, Felipe Araújo. Bourdieu encontra Pachukanis. Revista Direito e Práxis, Ahead of the print, Rio de Janeiro, 2019.

CHALHOUB, Sidney. Visões da liberdade: uma história das últimas décadas da escravidão na corte. São Paulo: Companhia das Letras, 1990.

DA SILVA, Virgílio Afonso. Interpretação constitucional e sincretismo metodológico. In: Virgílio Afonso da silva (Org.), Interpretação constitucional. São Paulo: Malheiros, 2005.

ENGELMANN, Fabiano. Sociologia do campo jurídico: juristas e os usos do direito. Porto Alegra: Sérgio Antônio Fabris, 2006.

FONTAINHA, F. C; OLIVEIRA, F. L; VERONESE, A. Por uma sociologia política do direito no Brasil. Revista Brasileira de Sociologia, v. 5, n. 11, 2017.

GOMES, Flávio dos Santos; SCHWARCZ, Lília Moritz. (Orgs.). Dicionário da escravidão e liberdade: 50 textos críticos. São Paulo: Companhia das Letras, 2018.

; GERALDO, P. H. B; VERONESE, A; ALVES, C. S; FIGUEIREDO, B. H; WALDBURGER, J. Processos seletivos para contratação de servidores públicos: Brasil, o país dos concursos?: relatório de pesquisa. Rio de Janeiro: Direito Rio, 2014.

; et al. O concurso público brasileiro e a ideologia concurseira. Revista Jurídica da Presidência, v. 16, n. 110, pp. 671-702, 2015.

GRAVER, Hans Petter. Why Adolf Hitler Spared the Judges: Judicial Opposition Against the Nazi State. German and law, v. 19, n. 4, pp. 845-878, 2018. 
KELSEN, Hans. Teoria pura do Direito. Tradução de João Machado. $8^{\text {a }}$ ed. São Paulo: Martins Fontes, 2012.

LYNCH, Christian Edward Cyril. Ascensão, fastígio e declínio da "revolução judiciarista". Insight Inteligência, v. 20, n. 79, pp. 158-168, 2017.

MACHADO, Maria Helena P. Toledo. Teremos grandes desastres se não houver providências enérgicas e imediatas: a rebeldia dos escravos e a Abolição da escravidão. In: GRINBERG, Keila e SALLES, Ricardo. (Orgs.). O Brasil imperial. V.3. Rio de Janeiro: Civilização Brasileira, 2009

MATOS, Andytias Soares de Moura Costa; RAMOS, Marcelo Maciel. A cultura jurídica brasileira: da exceção à atual promessa de emancipação. Quaestio Iuris, v. 9, n. 1, pp. 376-404, 2016.

MIGUEL, Luiz Felipe. Bourdieu e o "pessimismo da razão". Tempo Social, v. 27, n.1, 2014.

NEUMANN, Franz. The decay of German democracy. In: SCHEUERMAN (org.). The rule of law under siege: selected essays on Franz L. Neumann and Otto Kirchheimer. Los Angeles: University of California Press, 1996.

. O império do direito: teoria política e sistema jurídico na sociedade moderna. Tradução de Rúrion Soares Melo. São Paulo: Quartier Latin, 2013.

NEVES, Marcelo. Entre Hidra e Hércules: princípios e regras constitucionais. São Paulo: Martins Fontes, 2013.

SANTOS, Wanderley Guilherme dos. A democracia impedida: o Brasil do séc. XXI. Rio de Janeiro: FGV Editora, 2017. SARTORI, Vitor Bartoletti. Lukács e a crítica ontológica do Direito. São Paulo: Editora Cortez, 2010. 
SILVA, Eduardo. As camélia do quilombo do Leblon: uma investigação de história cultural. São Paulo: Companhia das Letras, 2003.

SCKELL, Soraya Nour. Os juristas e o direito em Bourdieu: a conflituosa construção histórica da racionalidade jurídica. Tempo Social, v. 28, n 1, 2014.

Recebido em 16/04/2019

Aprovado em 13/01/2020

Felipe Araújo Castro

E-mail: felipeacastro@gmail.com 
